\title{
LA ORALIDAD A PARTIR DE HISTORIAS DE VIDA \\ SOBRE LA DELINCUENCIA EN PERSONAS \\ QUE VIVEN EN SITUACIONES DE INDIGENCIA. \\ UNA MIRADA MULTIDISCIPLINAR SOBRE \\ LA CRIMINALIDAD DESDE EL DISCURSO \\ Y EL PSICOANÁLISIS
}

\author{
MARÍA LAURA PARDO \\ VIRGINIA BUSCAGLIA \\ CIAFIC-CONICET-Universidad de Buenos Aires
}

\section{RESUMEN}

En esta investigación pretendemos dar cuenta de las causas o motivaciones que llevan a diferentes sujetos a cometer delitos según narran en sus propias historias de vida. Estos sujetos viven en situación de calle y fueron entrevistados durante los años 2003 a 2011 en la ciudad de Buenos Aires. Partimos de una mirada multidisciplinar entre psicoanálisis y lingüística.

Nos interesan las historias de vida como una forma particular de la oralidad, que además nos permiten analizar, explicar e interpretar ejemplos sobre cómo dichos sujetos se relacionan con la culpa. Existen tres formas de enfrentarse a la culpa: 1) sentir culpa antes de delinquir: 2) sentir culpa frente al delito, 3) no sentir culpa. También hacemos hincapié en la desigualdad social como causal del delito.

Analizamos lingüísticamente la jerarquización de la información, especialmente el foco de las emisiones. El marco teórico es el del Análisis del Discurso y la metodología es cualitativa.

Palabras ClaVE: psicoanálisis, lingüistica, delito, pobreza, culpa.

\section{AbSTRACT}

In this research, we pretend to account for the causes or motivations that lead different subjects to commit crimes as they tell in their own life stories. These subjects live in street situations and were interviewed during the years 2003 to 2011 in the city of Buenos Aires. We start from a multidisciplinary perspective between psychoanalysis and linguistics.

We are interested in life stories as a particular form of orality, which also allow us to analyze, explain and interpret examples of how these subjects relate 
to guilt. One of the forms found is that of those who before the crime feel guilty. The second is that of those who feel no guilt about the crime. And the third is that of those who do not feel it. We also emphasize social inequality as the cause of crime.

We analyze linguistically the hierarchy of information, especially the focus of emissions. The theoretical framework is the Discourse Analysis and the methodology is qualitative.

KEYWORDS: psychoanalysis, linguistics, crime, poverty, guilty.

\section{INTRODUCCIÓN}

En este estudio nos proponemos dar cuenta de lo que las personas que viven en situación de pobreza narran acerca de las causas que los han llevado a cometer diferentes delitos, mediante una investigación multidisciplinar entre lingüística y psicoanálisis. Por lo que, en este estudio analizamos historias de vida, una forma de la oralidad que implica una interacción de mucha menos participación por parte de uno de los hablantes (el entrevistador), pero que permite indagar en la auto-presentación que el entrevistado realiza sobre sí y su entorno, y en este caso particular, sobre los delitos que ha llevado a cabo.

El marco teórico de este trabajo es el del Análisis Crítico del Discurso (ACD), en el que se sigue la vertiente latinoamericana (Garcia da Silva, 2015; Montecino, 2010; Resende de Melo, 2015; Pardo Abril, 2008; Pardo Gil, 2008, 2016). La metodología es cualitativa. El corpus consta de 5 historias de vida realizadas a personas que viven en situación de calle, en la que sus hablantes se refieren a hechos delictivos que han cometido. La teoría de análisis con que se lleva a cabo el análisis lingüístico es la noción de foco de la Jerarquización de la información (Pardo, 1986, 2011).

\section{Metodología}

La metodología es cualitativa. Se trata de un estudio de caso. El corpus está conformado por historias de vida grabadas en la ciudad de Buenos Aires (Argentina) a personas que viven en situación de calle. El período que comprende va desde el año 2003 hasta el 2011. De esta muestra, tomamos 5 historias de vida que consideramos son representativas para este caso.

Se trata de las siguientes historias de vida (los nombres de las personas involucradas en las historias de vida han sido cambiados por cuestiones éticas): 
1. SA, hombre, 25 años, ha estado preso por robo y homicidio ${ }^{1}$.

2. OC, hombre, 39 años, ha estado preso por robo y homicidio ${ }^{2}$.

3. OG, hombre, 45 años, ha robado (se sospecha que haya cometido abuso sexual) ${ }^{3}$.

4. OO, hombre, 52 años, homicidio (se sospecha que haya violado a dos niñas) ${ }^{4}$.

5. RR, hombre, 24 años, robo y homicidio ${ }^{5}$.

\section{ANTES DEL ANÁLISIS: LA NOCIÓN DE FOCO EN LA JERARQUIZACIÓN DE LA INFORMACIÓN}

La Jerarquización de la información es un principio del lenguaje que indica que todo en la lengua, o sea en el decir, está organizado jerárquicamente. Desde esta perspectiva, en los textos orales o escritos con los que se expresan los hablantes nunca existiría un grado cero (Barthes, 1953) en el que todos los recursos y estrategias lingüísticos quedan en igual orden, sino que, muy por el contrario, siempre hay algún grado de jerarquía.

Este orden jerárquico se da en dos planos:

a) en el de las emisiones: de los elementos que la conforman, algunos tienen una posición que los destaca; y

b) en el del texto: de todas las emisiones de un texto, algunas están más jerarquizadas que otras, algunas aparecen como más importantes de subrayar para el hablante.

Desde el análisis, la Jerarquización sigue el orden de palabras de una lengua. A aquello que es el punto de partida de la emisión (lo dado, lo compartido entre hablante y oyente) se lo denomina tema en tanto a aquello que se predica de eso dado se lo denomina rema.

En el español rioplatense podríamos decir que el orden de palabras es $\mathrm{VsO}$ (Verbo, sujeto en la desinencia verbal y Objeto) y la tendencia es hacia tener un patrón, un orden no marcado del tipo: tema-transición (que sería el verbo)-rema. Aunque, en general, como se omite el sujeto, esa posición inicial suele darse dentro del rema mismo. Sería un patrón del tipo: transición-tema-rema.

${ }^{1}$ SA tiene SIDA y ha sido drogadicto por años.

${ }^{2}$ OC es cardíaco, ex-drogadicto.

${ }^{3}$ OG ha perdido una pierna en un accidente de tránsito provocado por la policía, es ex-drogadicto, y ahora se ha convertido al Evangelismo.

4 OO se encuentra aún bajo caución juratoria.

${ }^{5}$ RR es ex-drogadicto. 
La noción de foco suele aparecer dentro de lo que se predica (rema), es la información que se supone apunta al objetivo comunicacional de la emisión. Está ligado también a cuestiones cognitivas relacionadas con la capacidad de retención de la información que se brinda en una emisión. Podría decirse que el foco está más fuertemente ligado al orden de palabras de una lengua, a su estructura, y vinculado al rema de una emisión.

Si consideramos que un hablante siempre coloca en posición final aquello que desea rematizar (siempre hablando de las lenguas romances [Halliday, 1967]), podemos afirmar que en muchos casos las posiciones finales son los conceptos que el hablante quiere hacer aparecer como más importantes para él; a ellas las llamamos remas. Pero dentro de los remas hay una posición que coincide con el sector final de la emisión, en general marcado por una forma suprasegmental y/o preposicional, que es lo que llamamos zona de foco. Este sector se corresponde con los últimos segundos que pueden ser memorizados por el hablante y con la información relevante del rema de una emisión; o sea, la que el hablante alcanza cuando logra su objetivo comunicacional y cierra la emisión.

En un esquema se observaría del siguiente modo:

$\frac{\text { tema } \quad \text { rema }}{\underline{\text { foco }}}$

Veamos un ejemplo:

La muñeca es muy linda y costosa

En este ejemplo, "La muñeca" es el tema, el punto de partida conocido por hablante y oyente, "es muy linda y costosa" es el rema, y el foco es "costosa”, que además está señalado por la conjunción “y”. Entonces, puede observarse que entre "linda" y "costosa", el término que está más jerarquizado es "costosa".

\section{LA POSTERGACIÓN DE LAS NECESIDADES PULSIONALES ${ }^{6}$ PARA PODER VIVIR EN COMUNIDAD}

Ya en 1950 Lacan, en colaboración con Michel Cenac, sostenían que la "humanización en el tratamiento del criminal sólo es posible si se parte de la idea de que el hombre se hace reconocer (se da a conocer ${ }^{7}$ ) por sus semejantes por los actos cuya responsabilidad asume" ya que "responsable"

\footnotetext{
${ }^{6}$ El término pulsión refiere al instinto humano.

7 Aclaración de las autoras.
} 
es la "persona que tiene que responder por sus actos"; y produce una fórmula: "la responsabilidad, es decir, el castigo". De esta manera, deja expuesta la relación de implicación entre responsabilidad y castigo. Y aclaran que más que hacer una contribución al estudio de la delincuencia, intentarán fijar los límites del aporte que puede realizar el psicoanálisis. Algo parecido intentamos nosotras. Ver en qué manera podemos aportar algo desde el ACD y con una mirada psicoanalítica.

El psicoanálisis nace en la modernidad, época que rompe con los cánones del romanticismo y que se ve reflejado en la subjetividad de esos nuevos tiempos. Esta sociedad favorece el devenir de un sujeto de la razón, anclado en una marcada rigidez moral y en fuertes prohibiciones. Es la época de los grandes ideales, de las metas a lograr a través del esfuerzo, es la época de "M'hijo el dotor".

Es en ese marco que Freud elabora su teoría; por lo tanto, el Yo freudiano refleja una sociedad como la que describimos arriba. Y con respecto al tema que nos convoca, es en esa época que escribe El malestar en la cultura (1930) haciendo referencia al malestar que provoca en el sujeto la postergación de las necesidades pulsionales ${ }^{9}$ para poder vivir en comunidad. Freud sostenía que la neurosis era, en cierta manera, una ética del sacrificio, ya que la vida en sociedad precisa de la renuncia pulsional que permita la convivencia. Sin represión no hay cultura. La agresividad constitutiva del ser humano, para formar parte de la cultura, es introyectada ${ }^{10}$ (mecanismo de defensa del Yo), lo que produce un conflicto con el Superyó ${ }^{11}$ que genera la culpa.

De ese yo freudiano pasamos al Yo postmoderno que ha sido construido en una sociedad de consumo en la que el mundo es considerado un depósito de potenciales objetos de consumo, que alienta la búsqueda de satisfacciones e induce a los individuos a creer que dar satisfacción a sus deseos de forma urgente es la regla que debe orientar sus elecciones. De este modo, se constituye como una necesidad existencial para lograr una vida válida y exitosa (Bauman, 2003). Esto implica ir en contra de la Ley,

\footnotetext{
8 "M'hijo el dotor" refiere a la obra teatral homónima (1903) de Florencio Sánchez en la que se narra la historia de una familia de inmigrantes cuya ambición más importante es la educación universitaria de su hijo. Al recibirse de médico, el hijo trata con desprecio, especialmente a su padre, dada la educación que ha recibido en Buenos Aires y que contrasta con el nivel educativo de sus padres, quienes viven en una zona rural. Sánchez intenta mostrar las diferencias entre dos miradas distintas sobre la vida en las que se contrapone la vida en la ciudad y en la zona rural, al igual que el enfrentamiento generacional. Finalmente, y ante la muerte de su padre, el hijo puede ver su error y se arrepiente.

${ }^{9}$ El Sujeto debe reprimir o sublimar la pulsión.

10 Introyectada refiere a incorporar.

11 El Superyó es la conciencia moral, que refiere en el inconsciente a los mandatos de los padres, la escuela, las instituciones, es decir, el Otro.
} 
romper el pacto social y, en consecuencia, fomentar el delito para cumplir con su deseo sin espera. Los ideales ya no organizan la vida del sujeto (o al menos de la mayoría). Este Yo postmoderno es individualista, con fuertes rasgos narcisistas y poca tolerancia a la frustración, que necesita satisfacer todas sus necesidades "ya" (sean necesidades de vivir emociones nuevas, como sucede con las adicciones, los juegos de riesgo, o la necesidad de obtener un bien inalcanzable, lo que lo lleva a obtenerlo de cualquier manera, ya que como dijimos no recurre a la represión para calmar sus pulsiones). Más que evitar el malestar, habría un goce en provocar dicho malestar, podríamos hacer un juego de palabras y hablar de El molestar a la cultura. Dicho molestar a la cultura, por ejemplo, fue logrado por el movimiento punk, que lo sublimó a través de sus expresiones artísticas, su forma de vestirse, de peinarse, todo era una manera de ir en contra de la cultura y de generar molestia en el otro, pero simbólicamente, sin matar al otro en lo real, lo mataban a través de expresiones que al común de la gente les resultaba hasta repulsivas.

Si bien aquella ética del sacrificio no ha desaparecido del todo, pues con ella lo haría la cultura, podríamos decir que el superyó ${ }^{12}$ actual no es el mismo que el teorizado por Freud. El nuevo superyó, más que plantear la renuncia como derivada del imperativo categórico ${ }^{13}$, ordena gozar: gozar a través de consumir, ilimitadamente, un gozar sin reglas ni ideales (Miller y Laurent, 1996).

\section{LOS QUE DELINQUEN POR SENTIMIENTO DE CULPABILIDAD ANTES DEL DELITO}

Uno de los textos freudianos más citados en lo que atañe al delito, la delincuencia, la criminalidad es "Los que delinquen por consciencia de culpabilidad" (1916). Freud sostiene que hay casos en que el sentimiento de culpa preexiste a la falta, la culpa no procede de la falta sino a la inversa, la falta proviene de la conciencia de culpa. A estas personas es lícito designarlas como "criminales por consciencia de culpabilidad". Según lo que hemos estado viendo sobre la culpa, como una especie de membresía para pertenecer a la sociedad, y la tensión creada entre el severo Superyó y el Yo subordinado al mismo, Freud califica ese comportamiento de ciertos delincuentes como "sentimiento de culpabilidad que se manifiesta bajo la necesidad de castigo".

${ }^{12}$ El superyó es, para Freud, una instancia que surge como resultado de la resolución del complejo de Edipo y constituye la internalización de las normas, reglas y prohibiciones parentales.

${ }^{13}$ Refiere al imperativo categórico kantiano. 
Pero si tomamos en cuenta todo lo expuesto sobre los cambios producidos en la subjetividad por la época actual, es válido pensar que esta culpa ya no se encuentra presente en el sujeto postmoderno (o como decimos siempre, no estaría presente en muchos sujetos, si no estaríamos hablando casi de un cambio filogenético más que sociocultural). Si estamos en la época del Otro que no existe, algo que escuchamos a diario ante determinadas situaciones cuando en el habla popular se dice "a nadie le importa un carajo el otro", "cada uno hace la suya y vos morite", hasta el extremo de llegar a situaciones de robo donde el delincuente, luego de haber recibido el dinero o los bienes que buscaba, igual mata a su víctima, evidentemente, la teoría freudiana relacionada con "los que delinquen por consciencia de culpabilidad" pareciera no encajar, del todo, en nuestros días.

De hecho, en nuestro análisis no encontramos personas que delinquen por un sentimiento de culpabilidad anterior al delito. Tampoco podemos indagar en el inconsciente de estas personas como para saber si tienen o no algún sentimiento de culpabilidad anterior.

\section{LOS QUE TIENEN CULPA Y LOS QUE NO}

Es a partir de conceptos tales como culpa, Yo postmoderno, nuevo Superyó, Ley, cultura, que intentaremos dar una explicación desde el psicoanálisis y la lingüística a la subjetividad implicada en el acto delictivo. Si bien debemos ser muy cuidadosas y evitar equiparar una descripción sociocultural con una manifestación singular del Sujeto con sus pulsiones y deseos, no debemos olvidar, como decía Lacan, que no hay Sujeto sin Otro, como lugar de lo simbólico, de la Ley (padres, familiares, amigos, maestros, jueces, autoridad, la religión o cualquier otra institución...cultura). Cuando todas estas instancias no vehiculizan la Ley, es decir, fallan, y el Sujeto las trasgrede, el único coto que existe para ello es la cárcel. En la cárcel, algunos de estos Sujetos encuentran la Ley divina.

A continuación, veremos dos casos contrapuestos que refieren a este encuentro con la Ley de Dios. Para este fin, y tal como lo mencionamos, utilizaremos la teoría de la Jerarquización y de ella tomaremos solo los "focos" (estos están señalados mediante letra cursiva).

\section{EJEMPLO 1:}

GO: 1 [Buen, mi vida empezó de los, los problemas, en la calle a los nueve años.] 2[Tuve problemas con drogas, con robos, con la policía o sea que, también, la policía me seguía por todos lados, peroooo cómo llegué acá?] 3[Llegué a la calle por, más por necesidad y por el accidente que me pasó...]

E: Aha. Y estar en la calle te ayuda porque te da.... 
GO: 4 [La misma mafia en el que yo estaba metida en la calle y todo eso... después de un tiempo me enteré que...la gente que me tiró abajo del tren había sido mandada por la policía... que nunca me, se me había pasado por la cabeza y bueno, tuve que, lo tuve que, me lo tomé como si nada, ¿no?] 5 [A pesar que a mí me falta una pierna, me faltan los dedos de un pie, me lo tomé como cosa que dios mandó a mi vida para que haga un parate.] 6 [O a la tumba o sino preso.] 7[Ninguna de las dos me tocó pero bueno, me tocó que me falté parte de mi cuerpo.] 8[También me enseñó, me enseñó a vivir cosas que no había pensado, que iba a vivir.] 9 [Tengo a mi abuela que le faltan las piernas...]

OG comienza su narración con la afirmación de que sus problemas se iniciaron en la calle siendo niño, y es su corta edad lo que deja en foco: "a los nueve años". Luego OG nos indica que robo, se drogó, que la policía lo perseguía, y él mismo pregunta replicando al entrevistador: "pero cómo llegue a acá" poniendo en foco dicha pregunta. En la siguiente emisión contesta señalando que llegó por necesidad, pero lo que queda remarcado, es decir en foco es: "y por el accidente que me pasó"; en consecuencia, fue el accidente que sufrió el que lo llevó a la situación en la que se encuentra.

Luego de convertirse al evangelismo en la cárcel ha cometido un robo y manifiesta sentimientos de culpa y vive el castigo de su accidente y pérdida de su pierna como la aplicación de la Ley divina; en cambio, en el ejemplo siguiente (ejemplo 2), OC no manifiesta en su discurso ninguna culpa (no nos referimos a la culpa inconsciente sino a algo del orden del arrepentimiento), siente la intervención divina como una oportunidad, de la que se considera merecedor ya que él se representa discursivamente como una persona buena.

Para que la ley no tenga que ser aplicada en la cárcel, que es una consecuencia traumática, hay que implementar los mecanismos para que las instituciones (incluida la familia) cumplan con su rol de vehiculizar la Ley.

En toda sociedad hay crimen y castigo, y este último exige por parte del que cometió el acto criminal un asentimiento subjetivo (Lacan, 1950) para que la pena cumpla su función. Es lo único que resignifica la pena y provoca alivio a quien ha cometido el delito.

En este caso observamos en el discurso de GO que él siente que pagó su delito, no a través de la cárcel, sino al quedarse sin una pierna por el accidente. GO valora más la ley divina (Dios), que la ley humana. GO interpreta la intervención divina como un castigo merecido y a su vez necesario para dejar de delinquir, es lo que le pone un "parate", tal como lo dice en el foco de la emisión ("e" de aquí en más) 5: "para que haga un parate”. El sujeto asiente subjetivamente su castigo. Obsérvese que los focos del texto remarcan el accidente, el cómo "me lo tomé como si nada, 
¿no?” en la e4, el "parate” al que aludíamos y luego a las partes de su cuerpo que se vieron afectadas (e7 "que me falte parte de mi cuerpo") al igual que lo que le sucedió a su abuela (e9 "que le faltan las piernas").

\section{EJEMPLO 2:}

GO: 1[Yo quiero las personas ahí no más.] 2[O sea no tengo... no tengo ningún prejuicio.] 3[Me tratan bien, yo las trato re bien.] 4 [Y creo que algo tiene que ver mi signo porque soy de libra.] 5[Soy muy abierto.] 6[Ahora me lastimaron, me quedó esa lastimadura, pero... a lo mejor vuelvo otra vez de vuelta, soy muy bueno.] 7[Soy muy bueno.] 8[A pesar de que... todas las macanas que me mandé.] 9[Soy muy bueno.] 10[Demasiado bueno soy.] 11[No tengo maldad...] 12[A lo mejor me rompen todo...]

E: ¿Estuviste en la cárcel?

OC: 1 [Sí.]

E: ¿En cuál fue?

OC: 2[Y estuve en la de Mendoza 8 años y acá en Azul estuve dos años]

E: ¿Alguna por homicidio o...?

OC: $3[$ No, no, no. Una por tentativa de robo y otra por... también, sí, por tentativa de homicidio, la primera.] 4[La primera, sí.] 5[Después me vine para acá...]

E: La primera sí, ¿qué? ¿La primera sí por intento de homicidio?

OC: 6 [Claro, en esa era tan maldito que no... no me quería ni yo mismo.] 7[Yo me escapé de la cárcel.] 8[No me agarraron nunca más.] 9[Ya ahora ya caducó la causa.] 10 [Ya puedo ir otra vez de vuelta a Mendoza tranquilamente.] 11 [Pero no, no nunca los hice los 8 años.] 12[Hice cuatro años, no más y después me escapé, me vine para Buenos Aires, estuve trabajando un tiempo acá.] 13 [La primera y última vez que trabajé.]

OC: 14 [No, no.] 15[Yo pienso que Dios me dejó para algo porque me dieron un itacazo, salí corriendo casi dos cuadras, de salí de los cañaverales... porque de mi casa, un poco más adelante, saliendo de los cañaverales hay una ruta; después del tiro que me metieron salí corriendo a los tiros, cruzo la... quiero cruzar la ruta y me atropella una ambulancia.] 16[Así que, mirá si...]

E: Una ambulancia, justo.

OC: 17[Una ambulancia, sí, la que me llevó, hasta Tigre.] 18[Uno lo cuenta y no te lo creen.] 19[Yo te lo digo, por personas que me vieron a mí, porque yo no me acuerdo nada.] 20[Yo sé que tenía estropeado todo, tengo una pata quebrada, el estómago, si yo te lo muestro, es un mapa.]

OC deja bien en claro en sus remas/focos (ya que son coincidentes en las emisiones $5 ; 6 ; 7 ; 9$ y 10), que es una persona muy buena (e6), demasiado buena (e10), abierta (e5), sin maldad (e11) (aunque luego en la historia de vida afirme que tiene mucho resentimiento hacia las personas). Sin embargo, a la hora de confesar su homicidio nunca aclara el porqué o 
lo justifica o muestra algún sentimiento de culpa o arrepentimiento. Más bien OC, a partir de sus focos, nos señala su camino discursivo: primero reconoce su tentativa de homicidio (solo la primera vez) 3[...la primera.]; 4 [... sí.]; luego se ocupa de contar su huida $5[\ldots$ para acá... $] ; 7$ [... de la cárcel.] 8[No me agarraron nunca más.] 9[Ya ahora ya caducó la causa.] 10 [Ya puedo ir otra vez de vuelta a Mendoza tranquilamente.] 11[Pero no, no nunca los hice los 8 años.] 12[... un tiempo acá.] 13[... última vez que trabajé.]

Un foco llamativo es el que está en la e6 [... no me quería ni yo mismo], ya que no encaja totalmente en el relato, se opone a su bondad como si en un pasado él hubiese sido tan malo como para no quererse ni a sí mismo. Esto podría visualizarse como una suerte de explicación a su tentativa de homicidio.

CO piensa que Dios lo dejó vivir por algo, pero no lo visualiza como un castigo, sino como que Dios le brinda una oportunidad más. Obsérvense que los focos resaltan su forma de huir y cómo una ambulancia que lo atropella es la que le salva su vida (e15) y cómo de mal quedó su cuerpo (e20).

EJEMPLO 3:

AS: 1[Yo cuando hicimos el ingreso, el chabón (QQ) me rescata, me dice "Toma, negro, negro, vení conmigo, vení que vos valés la pena, moreno"] 2 [...el chabón me cuidaba el culo a mí y yo le cuidaba el culo a él ¿̇me entendés?] ... (alguien quiere atacar a $\mathrm{QQ}^{14}$ ) 3 [“No, no, pero vos, vos qué te hacés el loquito, que esto que lo otro, pum, porque mirá” iplaf! deja la faca en la mesa.] 4[Y yo, y yo ahí te voy a hablar ahí yo agarré la faca de él misma lo maté, loco, se la puse en el medio del bobo, se la puse en el medio del bobo, del miedo, no fue de polenta, del miedo.] 5[Del miedo, te digo de verdad, del miedo, no fue de guapo, de cagón, de nada, de miedo, del miedo que yo tenía.]

Otro caso es el de AS, quien dice cometer el homicidio por "miedo" (e4) y no por lo que prejuiciosamente podría creerse por "polenta", es decir por matón, aunque sabemos que AS hace este juego discursivo de adelantarse a lo que pueda pensar el entrevistador y contarle que fue de otro modo, para blanquear su imagen. Esta misma afirmación de que lo hizo por miedo la podemos observar también en el foco de la e5. En este último, no solo está en foco "el miedo" sino que aparece tanto en posición temática como remática ${ }^{15}$ el temor: $5[\mathrm{Del}$ miedo, te digo de verdad, del mie-

14 Aclaración de las autoras.

${ }^{15}$ Hemos puesto en cursiva las palabras que aluden al miedo tanto en posición temática como remática. La palabra "guapo" alude en el español rioplatense no solo a una persona muy bonita, sino a quien es muy valiente. La palabra "cagón" se utiliza en el español rioplatense para referirse a aquel que tiene miedo. El uso es de este término es despectivo e insultante. 
do, no fue de guapo, de cagón, de nada, de miedo, del miedo que yo tenía.]. Es de notar también que dentro del foco aparece expresa la primera persona del singular asumiendo que era él quien tenía ese temor. Asumir el propio temor puede tomarse como una actitud cobarde que aquí funciona estratégicamente como un modo de autodefensa frente al intento de homicidio.

Seguimos observando ejemplos, como este, donde los delincuentes desenvisten de toda culpa a su acción homicida.

EJEMPLO 4:

OO: 1 [Bueno, mire, mi caso es único, creo que es único porque yo estuve preso 32 años.] 2[Caí a los 18 años y salí a los 49, hace 3 años que salí y bueno cuando salí ya no pude conseguir trabajo también por mi edad y bueno, como perdí toda mi juventud dentro de la cárcel... yo anduve en todas las cárceles de la república...]

E: Homicidio...

OO: 3[Fue homicidio, sí, fue homicidio.] 4[Y bueno, no..., no puedo...pude conseguir trabajo y encontré este lugar.]

OO: $5[$ No, no, no, no, aparte ya...] 6 [¿cómo le puedo decir? perdí todo el cariño, el afecto no..., no siento nada.] 7 [Sí... no..., no siento nada...]

OO, si bien reconoce que cometió un homicidio, en su discurso elude hablar del tema y parece restarle total importancia ya que lo pone en la misma jerarquía que con su falta de trabajo. En el foco de la (e3) es donde OO admite haber cometido un homicidio. En los dos focos anteriores podemos ver cómo se refiere a las consecuencias de haber cometido ese crimen, insistiendo en los años que pasó en la cárcel (e1) y en que recorrió todas las del país (e2). Llama la atención el hecho de que refiera que perdió todo el cariño y el afecto con mucha ambigüedad, puesto que en un primer momento parece aludir a un-os otro-s pero al decir que ya no siente nada (foco de la e6) nos damos cuenta que se refiere a su propio sentimiento de afecto y cariño. El no siente ya cariño, ni afecto, ni nada (e7).

EJEMPLO 5:

RR: 1 [Estuve en el Roca, en el San Martín... en el San Martín, en el Roca, en el Belgrano...] 2[Después de ahí estuve en comunidades, una comunidad terapéutica y hace poquito salí de la cárcel, estuve acá, en Ezeiza, por una causa que me... de un pibe que yo por brindarle un lugar donde yo estaba, el pibe mató a una persona y me hicieron causa a mi diciendo que yo lo ayude a matar al pibe y me pusieron a mí como cómplice de homicidio toda esas cosas, y muchas cosas y ahi ¿viste?] 3[Salí ¿viste? estuve un año y ocho meses detenido, un año y ocho meses estuve detenido y bueno, ahora quedó todo limpio pero ahora tengo otra causa abierta que dice que tengo un robo...] 
En este ejemplo se observa cómo RR se aparta del homicidio que cometió mediante frases como "me hicieron causa a mi diciéndome..." o "me pusieron a mí como cómplice" (foco de la e2). Nótese la cantidad de archipalabras en el foco de la (e2) que vuelven impreciso su decir: "todas esas cosas"; y "muchas cosas"; "ahî". Respecto del robo (foco de la e3): "que dice que tengo un robo". Todos "son decires" que lo vinculan supuestamente con el delito, pero él se desentiende de su culpabilidad. El Otro no importa, ni su muerte, ni su familia, no hay reflexión sobre la situación de aquel que mató. Solo importa la imagen, desentenderse del delito (como vimos en sus focos), en su individualismo extremo.

Estos cuatro ejemplos muestran que no existe en el discurso manifestación alguna de sentimiento de culpabilidad. Los hechos se narran brevemente y sin detalle alguno. Se transforman en un espacio interno imposible de evadir. Solo el primero siente culpa y arrepentimiento, y, curiosamente, es el único que solo comete un robo.

En esto acordamos con el ámbito del psicoanálisis, pero también de cierto sector del Derecho, que habla de que vivimos una época en la que se produjo la declinación del Nombre del Padre (esto en términos lacanianos) o la devaluación de la figura paterna, que no quiere decir otra cosa que la devaluación de La Ley, del Otro, de la ley simbólica, del pacto, ya que el padre siempre ha metaforizado la ley, es decir, el conjunto de normativas y prohibiciones a las que hay que sujetarse para ser parte de la cultura. Esto genera un modo particular de vincularse socialmente, a través de un individualismo extremo sin imágenes ideales con las que identificarse y sin poder incorporar el malestar que provoca la postergación de las necesidades pulsionales para poder vivir en comunidad. El ideal postmoderno es no tener ideal.

Estos sujetos, que acabamos de analizar, nacidos en la modernidad, y que buscan trabajos acordes, con esfuerzo, físicos, que no consiguen y que los han llevado a abandonar sus familias al no poder proveerlas, terminan en la calle. Una vez allí, este sujeto en el que conviven modernidad y postmodernidad, de a poco, van teniendo como principal objetivo el goce pulsional que solo se sostiene por fuera de la ley. No hay otra forma de sostenerlo.

Es decir, con la declinación del padre "estamos en la época del Otro que no existe" (Miller y Laurent, 1996).

\section{LA DESIGUALDAD SOCIAL COMO CAUSA DEL DELITO}

Las diferencias socio-económicas en esta sociedad posmoderna y la espectacularización (ostentación extrema) de la riqueza a través de los medios masivos de comunicación propenden a crear en los menos favorecidos sentimientos de inequidad y de injusticia social, por lo que se consideran 
merecedores, justamente, de un resarcimiento. Como tal resarcimiento nunca llega, así justifican sus actos delictivos.

Esto se relaciona con la famosa frase de Shakespeare, que retomara Freud en Los excepcionales:

La naturaleza ha cometido conmigo una grave injusticia negándome la bella figura que hace a los hombres ser amados. La vida me debe un resarcimiento que yo tomaré. Tengo derecho a ser una excepción, a pasar por encima de los reparos que detienen a otros. Y aún me es lícito ejercer la injusticia porque conmigo se la ha cometido (Ricardo III, William Shakespeare).

Veamos un ejemplo que muestra lo que acabamos de comentar:

EJEMPLO 6:

OG: 1[Gente que fue muy buena pero...adentro de ellos tenían cosas malas, ellos lo guardaban y llegaba un momento que explotaban y entonces, no les quedaba otra que agarrar un arma y salir a romper la cabeza a la gente de plata, tener autos grandes, autos lindos, por momentos, por momentos, balearse con la policía] 2[Claro.] 3[Muchas cosas] 4[Mucha ambición, ¿no?] 5[También].

OG: 6[Y la plata, tener más plata y más plata y más plata, o la droga llegar a tener más droga]. 7 [Siempre querés ser más, uno más que el otro, ¿no?] 8[Cómo es la sociedad, ¿no?] 9[La sociedad ahora es así.]

Este sujeto reflexiona acerca de cómo la sociedad actual (foco de la e8 y de la e9) sostiene la importancia del dinero, del poder a través del dinero. Tener autos grandes, lindos, tener plata, drogarse, querer ser más que el otro (foco de la e7). Y en ese querer ser más que el otro y no poder siquiera ser igual se hace visible la injusticia de la mala redistribución del dinero. Los focos están ligados a cuestiones que pueden ser también muestras de poder en el delito: (e1) balearse con la policía; (e6) tener cada vez más droga. Aquellos que no tienen, que están marginados, que son invisibles a los ojos del otro, pueden llegar a sentir mucho resentimiento, resentimiento que se argumenta para justificar el delito. Más allá de que el delito no deja de ser tal ni aun en este caso, el origen de la falta es algo que toda la sociedad debería replantearse y muy seriamente, sobre todo en estos momentos en que la inseguridad es tema de todos los noticieros, si no hay una deuda social con la gente que vive en situación de pobreza.

\section{Conclusiones}

Sin duda, el gran incremento de la brecha entre ricos y pobres, a favor de los primeros, en esta etapa de posmodernidad unida a la ostentación 
mediática de la riqueza, ubica a la mayoría de los ciudadanos en una situación de confrontación frente a la inequidad.

Todos los casos analizados mediante los focos de las emisiones muestran a sujetos que, habiendo cometido delitos graves como el homicidio, parecerían no sentir culpa, solo uno de ellos muestra asentimiento subjetivo de la pena. Sus relatos no hacen hincapié en el delito, lo eluden totalmente, ya que no favorecen a su imagen positiva frente al entrevistador. Más bien, en sus discursos abundan los recuerdos de una infancia en la que, si bien el dinero faltaba, los padres estaban ausentes, cualquier cosa es mejor que lo que vivieron después, y así podían sentirse "en cuna de oro". A partir de aquí, proyectan un futuro en el que la familia es el eje, pero con la condición de que ellos puedan ser los proveedores, sino será un nuevo fracaso. Esto sucede porque estos sujetos responden al gran mandato que lleva implícita la masculinidad: el hombre debe ser proveedor. Esta concepción moderna del trabajo se opone a la posmoderna, y enfrenta a estos sujetos a las consecuencias del neoliberalismo: la falta de trabajo, su redistribución y flexibilización. Por lo que, actualmente, hay sujetos que no trabajan y cuyos padres tampoco han tenido trabajo. Dos generaciones fuera de ese mandato laboral. El momento de quiebre de estos delincuentes es el momento en el que son echados del trabajo. Así, muchas veces el camino es delinquir, la droga, el alcohol, la cárcel y la calle. La inequidad observable en todo su entorno genera violencia y cuanta más es la inequidad, mayor es la violencia. Todos los han abandonado, su familia y la sociedad.

A nadie les importa ni su entorno, ni su pasado, y mucho menos darles una solución: educación y trabajo y, si fuese posible, un mundo más justo. 


\section{BIBLIOGRAFÍA}

Bauman, Z. (2003): Trabajo, consumismo y nuevos pobres, Barcelona, Gedisa.

Freud, S. (1979 [1916]): "Los que delinquen por consciencia de culpa", en $A l$ gunos tipos de carácter dilucidados por el trabajo psicoanalítico, Obras Completas, vol. XIV, Buenos Aires, Amorrortu.

Garcia DA Silva, D. E. (2015): "A política da desigualdade no Brasil: adolescentes em situação de rua”, en G. Lara y R. Lamberti (orgs.), Discurso e (des)igualdade social, Campinas, Contexto, págs. 1-93.

LACAN, J. y CENAC, M. (2013 [1950]): "Introducción teórica a las funciones del psicoanálisis en criminología”, en J. Lacan, Escritos 1, Madrid, Biblioteca Nueva, págs. 129-150.

Miller, J. A. y Laurent, E. (1996): El Otro que no existe y sus comités de Ética, Buenos Aires, Paidós.

Montecino Soto, L. A. (ed.) (2010): Discurso, pobreza y exclusión en América Latina. Santiago de Chile, Chile, Editorial Cuarto Propio.

Pardo Abril, N. (2008): ¿Qué nos dicen? ¿Qué vemos? ¿Qué es... pobreza? Análisis crítico de los medios, Bogotá, Universidad Nacional de Colombia.

Pardo GiL, M. L. (1996): Derecho y Lingüística. Cómo se juzga con palabras, Buenos Aires, Nueva Visión.

PARDo GIL, M. L. (2011): Metodología de la investigación lingüistica. Método sincrónicodiacrónico de análisis lingüistico de textos, Buenos Aires, Tersites.

Pardo GiL, M. L. (ed.) (2008): El discurso sobre la pobreza en América Latina, Santiago de Chile, Fasis Editores, págs. 79-97.

PARdo GIL, M. L. (2016): "Modernity, Postmodernity, Culture and Representations of Work in the Discourse of the Argentine Extremely Poor", en Shi-xu, K. Prah y M. L. Pardo (eds.), Discourses of the developing world. Researching properties, problems and potentials of the developing world, London, Routledge, págs. 154-164.

Resende DE Melo, V. (2015): "A violação de direitos da população em situação de rua e a violência simbólica: representação discursiva no jornalismo on-line”, Revista Latinoamericana de Estudios del Discurso, 15 (1), págs. 71-92. 